Observation satellite planned for the 1990s

\section{Tokyo}

JAPAN's National Space Development Agency (NASDA) plans to launch a large polar-orbiting Earth observation satellite in 1993 to monitor the Earth's ozone layer. If the plans come to fruition, the satellite will join two other polar-orbiting platforms, one part of the US space station project (see page 480) and the other built by the European Space Agency.

The Advanced Earth Observing Satellite (ADEOS) will be placed in orbit by an $\mathrm{H}-2$ rocket, and will carry an ocean colour and temperature sensor, a visible and near-infrared radiometer to observe land and coastal areas and an ozone sensor. Besides its global monitoring tasks, ADEOS will also participate in intersatellite communication experiments with the Engineering Test Satellite-VI, a geostationary communications satellite scheduled for launch in 1992. NASDA hopes to launch an experimental data relay and tracking satellite in 1994 to enable real-time communications with ADEOS when it is out of the range of ground tracking stations.

Most of the satellite will be built in Japan, but NASDA has invited international scientific participation in the development of the ozone sensor. Eight applications have been received from the United States, Italy, France and Australia. According to a NASDA official, the strongest proposal is from the US National Aeronautics and Space Administration (NASA), which wants to place a Total Ozone Measuring Sensor (TOMS) on $\mathrm{ADEOS}$

A TOMS sensor aboard NASA's Nimbus 7 satellite confirmed the existence of the hole in the ozone layer over the Antarctic two years ago after measurements from ground stations first indicated ozone loss, and this led to an international agreement to limit the use of chlorofluorocarbons. In August this year, NASA and the US Environmental Protection Agency met Toshio Horiuchi, the directorgeneral of Japan's Environment Agency, to discuss the possibility of carrying a TOMS sensor on ADEOS. But Shinichiro Ogura of the Science and Technology Agency, to which NASDA is affiliated, says a final decision on the sensor has not yet been made.

NASDA has applied for $¥ 520$ million (US\$4 million) for research and development of ADEOS during fiscal year 1989. A NASDA official estimates it will cost roughly US $\$ 400$ million to build the 3 -ton satellite.

David Swinbanks

\title{
French government approves abortion pill for commercial use
}

\section{Paris}

A DRUG which can be used to terminate an unwanted pregancy without the need for hospitalization has now been approved for commercial distribution in France. So far, China is the only other country to have given approval to this drug, known as RU486. But fears of an over-the-counter abortion pill (see Nature 325, 185; 1987) look to be unfounded. The French Ministry of Health approval, which was given last week, limits distribution of RU486 to selected clinics where strict precautions and follow-up should be assured.

RU-486, or mifepristone, was discovered in 1982 by a French researcher, Etienne Beaulieu, and is marketed by Roussel-Uclaf laboratories under the brand name Mifegyne. The drug acts by 'squatting' cells in the uterus which normally act as receptor sites for the hormone progesterone. Without progesterone the endometrial lining of the uterus breaks down, causing bleeding and stimulating the release of prostaglandins. The resulting muscle contractions usually lead to the embryo being expelled. It is this action, which prevents pregnancy being established that led Beaulieu to call the drug a 'contragestive' and not an abortifacient.

The French government approval contains several precautions to limit abuse as well as to enhance the effectiveness of RU-486. First, the drug may be administered only in association with prostaglandins. Clinical trials in France and abroad showed that a $600-\mathrm{mg}$ dose of RU486 alone led to successful expulsion of the embryo in about 80 per cent of cases but that the success rate is greatly improved if the dose is accompanied by prostaglandins, which aid contraction of the uterus

Second, the drug is to be given only during the first 49 days of pregnancy. After this time the woman's body produces too much progesterone for RU486 to be effective. Since 1974, abortion, usually by vacuum aspiration of the foetus, has been legally available in France in specialized family planning clinics, up to the twelfth week of pregnancy. Existing law requires an 8-day 'thinking period' once a woman has asked for her pregnancy to be terminated. This effectively means that a woman wishing to be given RU-486 must be able to satisfy doctors that she is less than four weeks pregnant. Currently, only about half of the 177,000 women seeking abortions each year would meet this criterion.

After the 8-day 'thinking period' a 600 mg dose (3 tablets) of RU-486 is taken orally in the presence of a doctor. Two days later, when bleeding should have begun, the doctor administers prostaglandins by intramuscular injection or with a vaginal suppository. The patient is than asked to return for an echograph to ensure that the embryo has been expelled. In the event that the drug has failed to terminate the pregnancy - a less than 3 per cent chance so long as RU-486 is associated with prostaglandins arrangements are then made for a conventional abortion.

According to Professor Roger Henrion, head of the maternity department at the Port-Royal hospital in Paris, who chaired the Ministry of Health commission, a woman who changed her mind at this stage and decided to have her baby would stand an as-yet unknown risk that the infant would be deformed. Studies in the rabbit have shown there is a risk that the non-expelled fetus will not develop normally and there has already been one case in France of a deformed baby being born to a woman who received RU-486 during pregnancy.

Henrion admits that a black market for RU-486 could emerge but hopes that the media will help emphasize that RU-486 "is not the painless trouble-free, do-ityourself abortion pill which some women have been led to believe. If what is stipulated by the government authorization is respected, I can only see an improvement in the choices available to women. But if this product finds its way out of these centres, or if doctors are not careful, very quickly there could be very serious risks."

According to Henrion, 18 to 20 per cent of women taking RU-486 continue to bleed for longer than 12 days. There are also risks that the embryo will not be expelled, or that the placenta will be retained, leading to infection. Henrion also fears the return of rhesus immunization, whereby a rhesus positive fetus of a rhesus negative mother induces production of antibodies which could endanger future pregnancies. Simple precautions are taken within the authorized clinics to overcome this risk.

French researchers are now looking at the effectiveness of RU-486 during the second cycle of ovulation as a means of birth control - its main function in China. The World Health Organisation has also asked that Roussel-Uclaf make the drug available at reduced cost to developing nations. In the meantime, in several other countries, including the Netherlands, Britain and Spain, application has been made to legalize RU-486 for abortion.

Peter Coles

See pages 492 and 543 of this issue for news of an effective contraceptive based on a sperm protein. 